\title{
Zika Virus Disease Cases - 50 States and the District of Columbia, January 1-July 31, 2016
}

\author{
William L. Walker, DVM, PhD ${ }^{1,2}$; Nicole P. Lindsey, $\mathrm{MS}^{2}$; Jennifer A. Lehman ${ }^{2}$; Elisabeth R. Krow-Lucal, PhD ${ }^{1,2}$; Ingrid B. Rabe, MBChB ${ }^{2}$; \\ Susan L. Hills, MBBS²; Stacey W. Martin, $\mathrm{MSc}^{2}$; Marc Fischer, $\mathrm{MD}^{2}$; J. Erin Staples, MD, $\mathrm{PhD}^{2}$
}

\begin{abstract}
On September 13, 2016, this report was posted as an MMWR Early Release on the MMWR website (http://www.cdc.gov/mmwr).
\end{abstract}

Zika virus is a mosquito-borne flavivirus primarily transmitted to humans by Aedes aegypti mosquitoes (1). Zika virus infections have also been documented through intrauterine transmission resulting in congenital infection; intrapartum transmission from a viremic mother to her newborn; sexual transmission; blood transfusion; and laboratory exposure (1-5). Most Zika virus infections are asymptomatic (1,6). Clinical illness, when it occurs, is generally mild and characterized by acute onset of fever, maculopapular rash, arthralgia, or nonpurulent conjunctivitis. However, Zika virus infection during pregnancy can cause adverse outcomes such as fetal loss, and microcephaly and other serious brain anomalies (1-3). Guillain-Barré syndrome, a rare autoimmune condition affecting the peripheral nervous system, also has been associated with Zika virus infection (1). Following the identification of local transmission of Zika virus in Brazil in May 2015, the virus has continued to spread throughout the Region of the Americas, and travel-associated cases have increased (7). In 2016, Zika virus disease and congenital infections became nationally notifiable conditions in the United States (8). As of September 3, 2016, a total of 2,382 confirmed and probable cases of Zika virus disease with symptom onset during January 1-July 31, 2016, had been reported from 48 of 50 U.S. states and the District of Columbia. Most cases (2,354; 99\%) were travelassociated, with either direct travel or an epidemiologic link to a traveler to a Zika virus-affected area. Twenty-eight (1\%) cases were reported as locally acquired, including 26 associated with mosquito-borne transmission, one acquired in a laboratory, and one with an unknown mode of transmission. Zika virus disease should be considered in patients with compatible clinical signs or symptoms who traveled to or reside in areas with ongoing Zika virus transmission or who had unprotected sex with someone who traveled to those areas. Health care providers should continue to educate patients, especially pregnant women, about the importance of avoiding infection with Zika virus, and all pregnant women should be assessed for possible Zika virus exposure at each prenatal visit (2).

On February 26, 2016, the Council of State and Territorial Epidemiologists (CSTE) approved interim case definitions for Zika virus disease and congenital Zika virus infection, adding them to the list of nationally notifiable conditions (8). This report includes confirmed and probable cases of Zika virus disease with illness onset during January 1-July 31, 2016 reported from U.S. states and the District of Columbia to ArboNET, the national arboviral surveillance system managed by CDC and state health departments. Cases were classified as confirmed or probable according to the clinical, epidemiologic, and laboratory testing criteria in the CSTE interim case definition (8). Infants with congenital infections were excluded; more information on congenital infections is available online (http://www.cdc.gov/zika/geo/pregnancy-outcomes.html).

As of September 3, 2016, a total of 2,382 confirmed and probable cases of Zika virus disease with illness onset during January 1-July 31, 2016 had been reported to ArboNET. Reports were received from 48 of 50 states and the District of Columbia (Figure 1). Half of all cases were reported from four states: New York (558 cases; 23\%), Florida (483; 20\%), California (147; $6 \%$ ), and Texas (117; 5\%). Overall, 1,495 (63\%) reported cases were in females (Table). The median age of Zika virus disease patients was 39 years (range $=1$ month -86 years) with $80 \%$ aged $20-59$ years.

Since January 1, 2016, a median of 49 cases (range $=22-207$ ) have been reported from U.S. states per week. The number of cases reported increased in May and continued to increase through July (Figure 2). Among all reported cases, 2,354 (99\%) were associated with travel, including 2,331 (98\%) with reported travel to an affected area and $23(1 \%)$ with sexual contact with a traveler to an affected area. The most frequent travel destinations were countries and territories in the Caribbean $(\mathrm{n}=1,545 ; 65 \%)$ followed by Central America (434; 18\%), South America (224; 9\%), North America (111; $5 \%)$, and Southeast Asia and the Pacific Islands $(11 ;<1 \%)$ (Table); 10 persons with Zika virus disease traveled to more than one region.

Among the 28 cases reported as locally acquired, 26 were associated with local mosquito-borne transmission. All 26 local cases of mosquito-borne disease were reported from Florida; patients ranged in age from 19 to 54 years, and 18 (69\%) were male. One case that was not mosquito-borne occurred in a researcher who had a needle stick exposure while working in a laboratory. The second case that was not mosquito-borne occurred in a patient for whom the mode of transmission is not yet known but who had close personal contact with a family contact with travel-associated Zika virus disease; the family 
FIGURE 1. Number of confirmed and probable Zika virus disease cases reported from U.S. states and the District of Columbia January 1-July 31, 2016

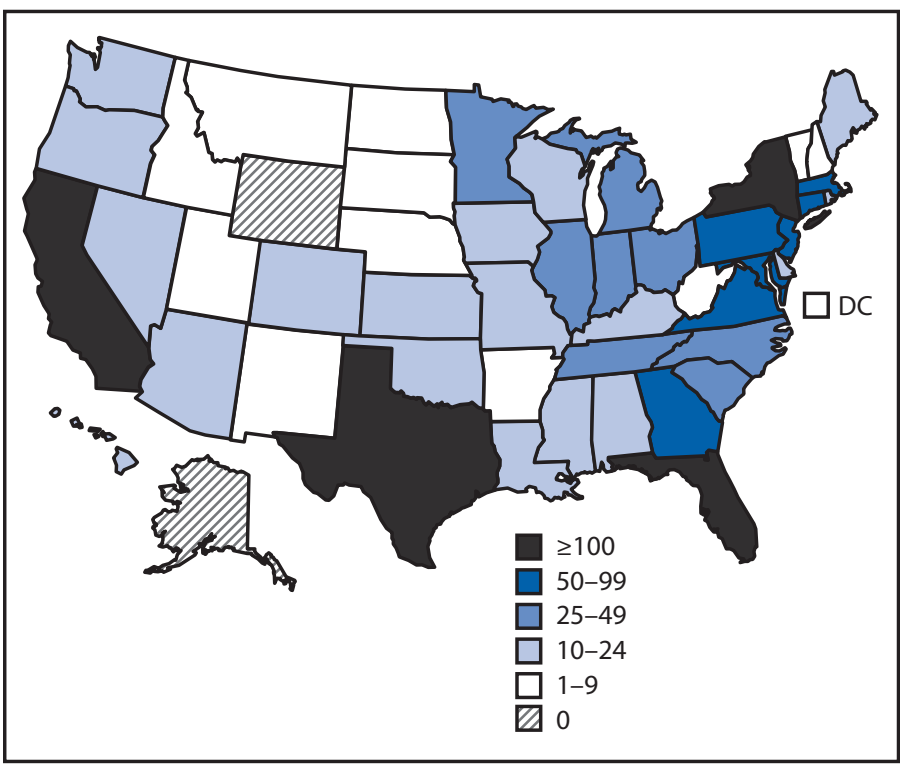

TABLE. Characteristics of 2,382 confirmed and probable cases of Zika virus disease reported from 48 U.S. states and the District of Columbia - January 1-July 31, 2016

\begin{tabular}{lr}
\hline Characteristic & No. (\%) \\
\hline Sex & \\
Female & $1,495(63)$ \\
Male & $886(37)$ \\
Unknown & $1(<1)$ \\
Age group (yrs) & \\
$0-19$ & $208(9)$ \\
$20-39$ & $1,012(42)$ \\
$40-59$ & $889(37)$ \\
$\geq 60$ & $273(11)$ \\
Region visited during travel* & \\
Caribbean & $1,545(65)$ \\
Central America & $434(18)$ \\
South America & $224(9)$ \\
North America & $111(5)$ \\
Southeast Asia and Pacific Islands & $11(<1)$ \\
No direct travel ${ }^{\dagger}$ & $51(2)$ \\
Unknown & $16(<1)$ \\
Clinical outcome & \\
Hospitalized & $65(3)$ \\
Died & $1(<1)$ \\
\hline
\end{tabular}

* Sum exceeds $100 \%$ because of exposures in multiple regions during travel.

† Includes sexually transmitted cases and locally acquired cases.

contact had a level of viremia approximately 100,000 times higher than average and subsequently died (9).

Sixty-five (3\%) patients with Zika virus disease were hospitalized, and one patient died (9). The 65 hospitalized patients were reported from 16 states and had a median age of 44 years (range $=1$ month-86 years); 44 (68\%) were female. Detailed information about hospitalization was available for 27 (42\%) hospitalized patients. The median duration of hospitalization
FIGURE 2. Number of confirmed and probable Zika virus disease cases reported from U.S. states and the District of Columbia, by month of illness onset and source of infection - January 1-July 31, 2016

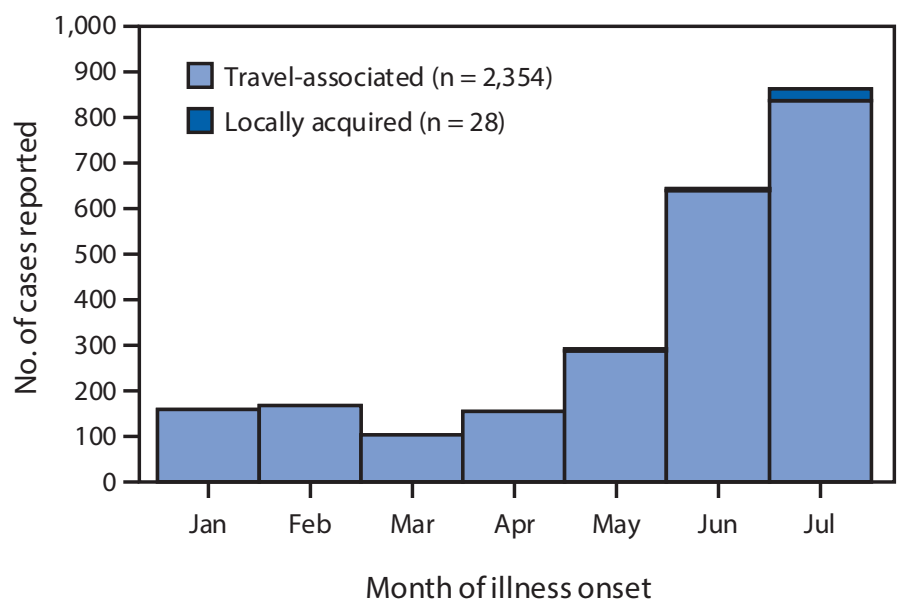

was 3 days (range $=1-7$ days). Documented reasons for hospitalization included viral illness (11 patients), neurologic manifestation (six), need for further clinical evaluation (six), possible respiratory infection (two), exacerbation of underlying medical condition (one), and septic shock (one). The six patients with neurologic manifestations included five patients with Guillain-Barré syndrome and one with paresthesia. All hospitalized patients were discharged, with the exception of the patient with septic shock, who developed multiple organ failure and died in the hospital (9).

\section{Discussion}

The number of travel-associated Zika virus disease cases reported from U.S. states has increased markedly; 2,354 cases were reported during the first 7 months of 2016, compared with only 11 cases during 2010-2014 and 24 in 2015 $(7,10)$. In July 2016, the first local mosquito-borne transmission of Zika virus in the continental United States was reported in Florida.

The demographic characteristics of Zika virus disease cases reported by U.S. states are similar to those reported from other countries. The age distribution of cases is similar to that reported for U.S. travelers infected with other Aedes aegyptiborne viral diseases (chikungunya and dengue). Sixty-three percent of cases reported from U.S. states in 2016 have been in females, similar to the proportion of symptomatic cases in females (61\%) reported in Yap, Micronesia (6). The higher proportion of women with symptomatic disease might be because of care-seeking behavior, differential exposure to mosquitoes or sexual transmission, or increased testing of pregnant women.

The findings in this report are subject to at least three limitations. First, the number of cases are likely underestimated because most symptomatic Zika virus infections are mild, 
and infected persons might not seek health care or be tested. Second, because ArboNET does not require information about clinical signs and symptoms or laboratory findings, it is possible that cases could be misclassified. Finally, the number of cases in this report should be considered preliminary, particularly as cases might be reclassified based on revisions to the case definition for Zika virus disease that were approved by CSTE in June 2016.*

Recent outbreaks of Zika virus disease have identified new modes of transmission and clinical manifestations, including adverse pregnancy and birth outcomes (1). CDC has issued guidance to reduce the risk for Zika virus infections and to aid in the diagnosis ${ }^{\dagger}$ and management of cases, particularly among pregnant women, sexual contacts of travelers, and among infants (2-4). The Food and Drug Administration recommends temporary deferral of blood donations from persons who recently traveled to areas with Zika virus transmission, as well as testing of all blood donations collected in the United States and its territories to reduce the risk for transfusion-associated transmission of Zika virus (5). Providers should continue to consider Zika virus disease in patients with compatible clinical signs or symptoms and who traveled to or reside in areas with ongoing transmission or had sex without a condom with someone who traveled to or resides in those areas; these areas currently include specific areas of Florida. ${ }^{\$}$ All pregnant women should be assessed for possible Zika virus exposure at each prenatal care visit. Zika virus testing should be offered to asymptomatic pregnant women who traveled to or live in an area with active Zika virus transmission, or who had sex without using condoms to prevent infection with a partner who has traveled to or resides in an area with active Zika virus transmission (2).

Providers are encouraged to contact their state or local health departments to report suspected cases and to obtain guidance on laboratory testing and assistance with interpretation of test results. To mitigate the risk for spread of Zika virus, health care providers should continue to educate patients about the risks of Zika virus infection and steps they can take to prevent infection. Additional information is available at http://www. cdc.gov/zika/index.html.

\footnotetext{
*http://c.ymcdn.com/sites/www.cste.org/resource/resmgr/2016PS/16_ID_01_ edited7.29.pdf.

${ }^{\dagger}$ http://www.cdc.gov/zika/laboratories/lab-guidance.html.

${ }^{\S} \mathrm{http}: / /$ www.floridahealth.gov/diseases-and-conditions/zika-virus/index.html.
}

\section{Summary}

What is already known about this topic?

Zika virus disease is an arboviral disease usually causing mild illness; however, congenital infection is associated with birth defects. Although most cases in U.S. residents are travel-associated, local transmission has been reported.

What is added by this report?

As of September 3, 2016, a total of 2,382 confirmed or probable cases of Zika virus disease with symptom onset during January 1-July 31, 2016 were reported to ArboNET, the national arboviral surveillance system managed by CDC and state health departments. Most (99\%) cases were travel-associated. Locally acquired cases include 26 mosquito-borne disease cases, one laboratory-acquired infection, and one patient with unknown transmission mode. Sixty-five (3\%) patients were hospitalized, and one died.

What are the implications for public health practice?

Health care providers should continue to educate patients, especially pregnant women, about the importance of avoiding infection with Zika virus, and all pregnant women should be assessed for possible Zika virus exposure at each prenatal visit. Zika virus disease should be considered in patients with compatible clinical signs or symptoms who traveled to or reside in areas with ongoing Zika virus transmission or who had unprotected sex with someone who traveled to those areas.

\section{Acknowledgments}

State and local health departments reporting to ArboNET and the Zika Virus Response Epidemiology and Laboratory Team.

\footnotetext{
${ }^{1}$ Epidemic Intelligence Service, CDC; ${ }^{2}$ Arboviral Diseases Branch, Division of Vector-Borne Diseases, National Center for Emerging and Zoonotic Infectious Diseases, CDC

Corresponding author: J. Erin Staples, auv1@cdc.gov, 970-221-6400.
}

\section{References}

1. Frieden TR, Schuchat A, Petersen LR. Zika virus 6 months later. JAMA 2016. Epub August 8, 2016. http://dx.doi.org/10.1001/jama.2016.11941

2. Oduyebo T, Igbinosa I, Petersen EE, et al. Update: interim guidance for health care providers caring for pregnant women with possible Zika virus exposure-United States, July 2016. MMWR Morb Mortal Wkly Rep 2016;65:739-44. http://dx.doi.org/10.15585/mmwr.mm6529e1

3. Russell K, Oliver SE, Lewis L, et al. Update: interim guidance for the evaluation and management of infants with possible congenital Zika virus infection—United States, August 2016. MMWR Morb Mortal Wkly Rep 2016;65:870-8. http://dx.doi.org/10.15585/mmwr.mm6533e2

4. Brooks JT, Friedman A, Kachur RE, LaFlam M, Peters PJ, Jamieson DJ. Update: interim guidance for prevention of sexual transmission of Zika virus-United States, July 2016. MMWR Morb Mortal Wkly Rep 2016;65:745-7. http://dx.doi.org/10.15585/mmwr.mm6529e2 
5. Food and Drug Administration. Revised recommendations for reducing the risk of Zika virus transmission by blood and blood components: guidance for industry. Rockville, MD: Food and Drug Administration; 2016. http://www.fda.gov/downloads/BiologicsBloodVaccines/ GuidanceComplianceRegulatoryInformation/Guidances/Blood/ UCM518213.pdf

6. Duffy MR, Chen TH, Hancock WT, et al. Zika virus outbreak on Yap Island, Federated States of Micronesia. N Engl J Med 2009;360:253643. http://dx.doi.org/10.1056/NEJMoa0805715

7. Armstrong P, Hennessey M, Adams M, et al. Travel-associated Zika virus disease cases among U.S. residents-United States, January 2015February 2016. MMWR Morb Mortal Wkly Rep 2016;65:286-9. http://dx.doi.org/10.15585/mmwr.mm6511e1
8. Council of State and Territorial Epidemiologists. Zika virus disease and congenital Zika virus infection interim case definition and addition to the Nationally Notifiable Disease List. Atlanta, GA: Council of State and Territorial Epidemiologists; February 2016. https:/www.cste2.org/docs/ Zika_Virus_Disease_and_Congenital_Zika_Virus_Infection_Interim.pdf 9. Brent C, Dunn A, Savage HM, et al. Preliminary findings from an investigation of Zika virus infection in a patient with no known risk factors-Utah, 2016. MMWR Morb Mortal Wkly Rep 2016. In press.

10. Hennessey MJ, Fischer M, Panella AJ, et al. Zika virus disease in travelers returning to the United States, 2010-2014. Am J Trop Med Hyg 2016;95:212-5. http://dx.doi.org/10.4269/ajtmh.16-0049 